\title{
Polymorphism Evaluation in Generic Tablets containing Mebendazole by Dissolution Tests
}

\author{
Sara B. Honorato, ${ }^{*}, a$ Silvia Farfan, ${ }^{b}$ Arnaldo Viana,${ }^{c}$ Josué M. Filho, ${ }^{a}$ Gisela C. Camarão, ${ }^{c}$ \\ Francisco V. Fechine, ${ }^{c}$ Maria E. A. Moraes, ${ }^{c}$ Manoel O. Moraes, ${ }^{c}$ Maribel Ferro, ${ }^{b}$ \\ Viviana Dabbene, ${ }^{b}$ Silvia L. Cuffini ${ }^{b, \#}$ and Alejandro P. Ayala ${ }^{a}$ \\ ${ }^{a}$ Department of Physics, Federal University of Ceará, CP 6030, 60455-760 Fortaleza-CE, Brazil \\ ${ }^{b}$ Subsecretaria CEPROCOR, Ministerio de Ciencia y Tecnologia, Córdoba, Argentina \\ ${ }^{c}$ Department of Physiology and Pharmacology, School of Medicine, Federal University of Ceará, \\ CP 3157, 60430-270 Fortaleza-CE, Brazil
}

\begin{abstract}
Este estudo avalia a incidência de formas polimórficas do mebendazol (MBZ) em comprimidos do mercado brasileiro por testes de dissolução. O meio de dissolução indicado pela USP 30 (United States Pharmacopeia) e um meio modificado proposto foram devidamente comparados a fim de verificar se eles são capazes de diferenciar o polimorfo A do polimorfo C em comprimidos comerciais. Ensaios de testes de dissolução de misturas físicas em matérias-primas do polimorfo A e C, assim como de nove comprimidos de MBZ (disponíveis no mercado brasileiro), foram devidamente executados. Para os testes de dissolução, o meio da USP 30 (I) e um meio modificado (II) foram utilizados. O meio modificado permitiu uma reprodutibilidade e controle da qualidade confiável do polimorfismo do MBZ em comprimidos comerciais.
\end{abstract}

This study evaluates the incidence of the polymorphic forms of mebendazole (MBZ) in tablets within the Brazilian market by dissolution tests. The indicated dissolution medium by the USP 30 (United States Pharmacopoeia) and a proposed modified medium were duly compared in order to verify whether they are able to discriminate the polymorph $\mathrm{A}$ from polymorph $\mathrm{C}$ in commercial tablets. Dissolution assay tests of physical mixtures in raw materials of polymorph A and polymorph C, as well as of nine tablets of MBZ (available in the Brazilian market), were properly performed. For the dissolution tests, the USP 30 medium (I) and a modified medium (II) were used. The modified medium allowed a reproducible and reliable quality control of MBZ polymorphism in commercial tablets.

Keywords: mebendazole, polymorphism, solubility, Raman spectroscopy, X-ray powder diffraction

\section{Introduction}

Roundworms, whipworms and hookworms infections are the most prevalent neglected tropical diseases. ${ }^{1}$ Recent estimates indicate that one quarter of the world's population is infected with one or more of these said parasites, ${ }^{2,3}$ giving rise to a combined disease burden that might be as large as those of malaria or tuberculosis. ${ }^{4,5}$ Due to this, the World

\footnotetext{
*e-mail: sara_honorato@ fisica.ufc.br

"Current address: Laboratório de Controle da Qualidade, Departamento de Ciências Farmacêuticas, Centro de Ciências da Saúde Campus Universitário Trindade, Universidade Federal de Santa Catarina, 88040-900 Florianópolis-SC, Brasil
}

Health Organization (WHO) and others have advocated the implementation of deworming programs, targeting these infections simultaneously. Recently, a detailed analysis of the randomized and controlled trails that were reported in the literature supported the initiative from WHO. ${ }^{1}$ Deworming programs were beneficiated by the expiration of patents in several anthelmintic drugs (for example, mebendazole, albendazole and praziquantel), whereby their generic versions are now available at very low costs. ${ }^{4,6}$

Mebendazole [(5-benzoyl-1H-benzimidazol-2-yl)carbamic acid methyl ester (MBZ), Figure 1] is a broad spectrum anthelmintic drug, producing high cure rates in infestations by roundworms, threadworms, hookworms and 
whipworms. ${ }^{7}$ The wide spectrum of activity, high efficiency and ease in administration as exhibited by MBZ mean that it is now widely used in large scale deworming programs, being most of them focused at school-aged children in developing countries. ${ }^{6.8}$ Due to the impact of such programs on the quality of life with the above mentioned children, MBZ was included by WHO in the Model List of Essential Drugs as a reference for similar clinical performances within the intestinal anthelmintics pharmacological class. ${ }^{9}$

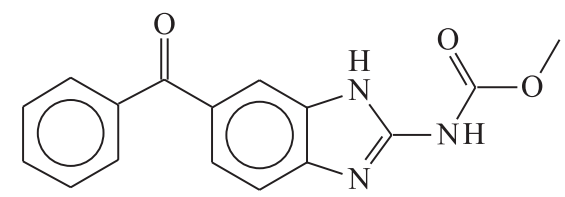

Figure 1. Chemical structure of MBZ.

The widespread use of MBZ and albendazole for treating intestinal nematode infections in human populations is raising concerns for a more cautious monitoring procedure (to be in place) in order to identify any emergence of a drug resistance. ${ }^{4,10,11} \mathrm{~A}$ factor that must be considered in this problem is the quality of the anthelmintic drugs since low quality medication would not only contribute to the failure of the deworming programs but would also contribute to the emergence of drug resistance. Therefore, drug quality is critical, especially in developing countries where generic anthelmintics are both imported and locally produced. Tablets may vary in properties such as purity, disintegration, dissolution and bioavailability, thus, affecting the therapeutic results.

A factor that may contribute to the variability in the efficiency of the pharmaceutical formulation is the polymorphism in the active pharmaceutical ingredient (API). Polymorphism is the ability of a chemical compound to exist in more than one crystal form. ${ }^{12}$ The different structural arrangements of the drug are followed by changes in the physicochemical properties, which may affect its bioavailability, manufacturability, purification, stability and other performance characteristics of the API. ${ }^{13}$ Considering the benzimidazole carbamates commonly applied in deworming programs, the MBZ and the albendazole, only the former exhibits polymorphism. In the solid state, MBZ crystallizes in three polymorphic forms, namely the polymorphs A, B and C. Several authors pointed out possible differences in the bioavailability of the polymorphs of MBZ..$^{14,15}$ Despite of some discrepancies in the literature about the relative solubility of forms B and C, all the relevant authors agree that form $\mathrm{A}$ is the least soluble one. ${ }^{14,16,17}$ Therefore, form $\mathrm{C}$ is pharmaceutically preferred since its solubility is sufficiently enough to ensure optimal bioavailability without exhibiting the associated toxicity to form B. ${ }^{14,16-18}$ Furthermore, a therapeutic trial that was performed on 958 school-aged children in Thailand using a placebo and the MBZ polymorph A and polymorph $\mathrm{C}$ suggested that form A has a similar efficiency to the placebo in the controlling of hookworms and whipworms infections. ${ }^{14}$ However, the authors also reported the polymorph dependence on the anthelmintic efficacy results for MBZ. So, they duly proposed that at least $30 \%$ of form $\mathrm{A}$ in the formulation is enough to suppress the desirable pharmacological activity. ${ }^{15,19}$ Brits et al..$^{20}$ recently performed a study investigating the influence of temperature and moisture on the polymorph transformations of form $\mathrm{C}$ going into form A in MBZ tablets. These aforementioned authors observed that, with increasing of temperature and humidity, form $\mathrm{C}$ is converted into form $\mathrm{A} .{ }^{20}$ This transformation is significantly increased in the presence of traces of form $\mathrm{A} .{ }^{20}$

In order to understand the problems associated with the formulation of MBZ, firstly it is necessary to briefly consider the quality control requirements for these tablets. ANVISA (Agência Nacional de Vigilância Sanitária, the Brazilian regulatory agency), as well as many other agencies around the world, published an official monograph describing the tests in order to ensure the quality of MBZ. ${ }^{21,22}$ Due to the limited solubility of this drug in water and organic solvents, fact that affects its absorption and behavior in bodies, the Brazilian and United States Pharmacopeias (USP) require a dissolution test, which must identify different MBZ polymorphs. The dissolution medium prescribed by the USP 30 is $900 \mathrm{~mL}$ of $0.1 \mathrm{~mol} \mathrm{~L}^{-1}$ hydrochloric acid, containing $1 \%$ sodium lauryl sulfate (SLS). Dissolution media for water insoluble drugs generally contain the surfactant SLS in order to aid in the dissolution processess. ${ }^{23}$ Under these conditions, SLS enhanced the solubility of this poorly water-soluble drug due to wetting and/or micellar solubilization. Several authors also verified that the above described dissolution test has no sensitivity to identify the crystal forms. ${ }^{15,18,24}$ Therefore, the necessity of modifying the USP dissolution test for the purpose of adapting it to discriminate the MBZ polymorphs was repeatedly pointed out. Swanepoel et al. ${ }^{18}$ investigated the influence of the dissolution medium in the effectiveness of the USP test, showing that the dissolution properties of the three polymorphs are equal in the USP medium (more than $75 \%$ dissolved after $120 \mathrm{~min}$ ). If the surfactant is not used in the medium, the polymorphs exhibited uneven dissolution profiles. The most soluble form was the polymorph C (75\% dissolved after $120 \mathrm{~min}$ ), followed by the polymorphs B (37\% dissolved after $120 \mathrm{~min}$ ) and A (20\% dissolved after $120 \mathrm{~min}$ ). Additionally, the modified dissolution medium provides a method to discriminate within the MBZ polymorphs. 
Brazil (such as other South American countries) has adopted a generic drug program since 1999. In order to evaluate the incidence of MBZ polymorphs in the Brazilian market, we have duly investigated nine different MBZ tablets. The crystal form used in the formulation of the tablets was determined by X-ray powder diffraction (XRPD) and Raman spectroscopy. ${ }^{25-27}$ Dissolution tests based on the USP 30 and the modified medium were performed to define the sensitivity of these stated methods to the crystal form. Furthermore, different physical raw material mixtures of forms $\mathrm{A}$ and $\mathrm{C}$ were measured in order to assay the influence of the relative concentration in the dissolution profile.

\section{Experimental}

\section{Materials}

Mebendazole raw material crystallized on form A and form C was kindly provided by Red Pharm. Commercial tablets containing $100 \mathrm{mg}$ of the API were directly obtained from the market. All the tablets used in this study and research fulfilled pharmaceutical specifications and have at least two years of validity.

\section{Instrumentation}

The used polymorph in the formulation of the above stated tablets was determined by the XRPD and the Raman spectroscopy. X-ray powder patterns were obtained using a Bruker AXS D8 Advance X-ray diffractometer. The Raman spectra were recorded from the original samples on a Bruker VERTEX 70 FTIR/FT-Raman spectrometer, equipped with a Nd:YAG laser (1064 nm excitation line) and a liquid-nitrogen cooled Ge detector. The determination of the dissolved drug was carried out using a Shimadzu ${ }^{\circledR}$ UV/Visible spectrophotometer (model 1602).

\section{Dissolution studies}

All the presented dissolution researches in this study were performed using the paddle method (USP 30 apparatus 2). All reagents were of analytical grade. The temperature of the medium was kept at $37.0 \pm 0.5^{\circ} \mathrm{C}$. The paddles were rotated at $75 \mathrm{rpm}$ and the samples were withdrawn from the dissolution medium at 5, 10, 15, 30, 60 and $120 \mathrm{~min}$. Two dissolution media were used in the solubility tests: medium I, $1 \mathrm{~mL}$ of samples in $9 \mathrm{~mL}$ of $0.1 \mathrm{~mol} \mathrm{~L}^{-1}$ hydrochloric acid and sodium dodecyl sulfate (SDS) $1 \%$, and medium II, $1 \mathrm{~mL}$ of the samples in $4 \mathrm{~mL}$ of $0.1 \mathrm{~mol} \mathrm{~L}^{-1}$ hydrochloric acid. The dilutions were carried out in glass test tubes: 1:10 for the samples dissolved in the medium I and 1:5 for the samples dissolved in the medium II. The solutions were also assayed with the Spectrophotometer UV at $248 \mathrm{~nm}$.

Dissolution tests in the mixtures of raw materials (similar particular size distributions) of MBZ forms $\mathrm{A}$ and $\mathrm{C}$ were performed starting with suspensions, having concentrations ranging from $100 \%$ of form $\mathrm{A}$ to $100 \%$ of form $\mathrm{C}(0,10$, 50,90 and $100 \%$ of form C). In each of the experimental stages (I and II media), $50 \mathrm{~mL}$ of the solution medium were added. The solution was agitated using a vortex mixer, and immediately thereafter, put into a dissolution vat, in which there were $900 \mathrm{~mL}$ of the dissolution medium at $37^{\circ} \mathrm{C}$. This is performed in order to accomplish the aforesaid dissolution test, according to experimental conditions. In this particular case, the samples were withdrawn from the dissolution medium at 5, 10, 15, 30, 45, 60, 90 and 120 min.

\section{Data analysis methodology}

The dissolution curves for both polymorphs, as well as for drugs, were compared using well-known modelindependent methods. The difference factor $\left(f_{l}\right)$ proposed by Moore and Flanner ${ }^{28}$ calculates the difference in percentage of two curves at each time point and it is a measurement of a relative error in these two curves. The $f_{l}$ was determined by:

$$
f_{1}=\left[\frac{\sum_{j=1}^{n}\left|R_{j}-T_{j}\right|}{\sum_{j=1}^{n} R_{j}}\right] \times 100
$$

where $n$ is the number of time points, $R_{j}$ and $T_{t}$ are the values of dissolution in the reference and test batches at time $t$, respectively.

The similarity factor $\left(f_{2}\right)^{28}$ was calculated using:

$$
f_{2}=50 \times \log \left\{\left[\frac{1}{\sqrt{1+\left(\frac{1}{n}\right) \sum_{j=1}^{n}\left(R_{j}-T_{j}\right)^{2}}}\right] \times 100\right\}
$$

where $n$ is the number of time points recorded in the dissolution profile of each sample, $R_{j}$ and $T_{j}$ are the dissolution values of the reference and test batches at time $t$, respectively. The similarity factor $f_{2}$ is a logarithm of the reciprocal square root of the sum of the squared errors. The dissolution of the test and of the reference batches were exactly performed in the same conditions. Curves are considered similar if $f_{2}$ values are larger than $50 \%$.

\section{Results and Discussion}

In order to determine the crystal form used in the formulation of commercial tablets, the XRPD and the 
Raman scattering measurements were performed in the duly investigated samples. It is well-known that both experimental methods have enough sensitivity to distinguish the polymorph of MBZ. ${ }^{25,27}$ The representative $\mathrm{X}$-ray powder patterns and the Raman spectra are shown in Figure 2. According to these stated results, it was observed that from the nine different branded tablets that were used in this study, eight were formulated using form A (samples identified as MBZ 2 to MBZ 9) and one using form C (sample identified as MBZ 1).
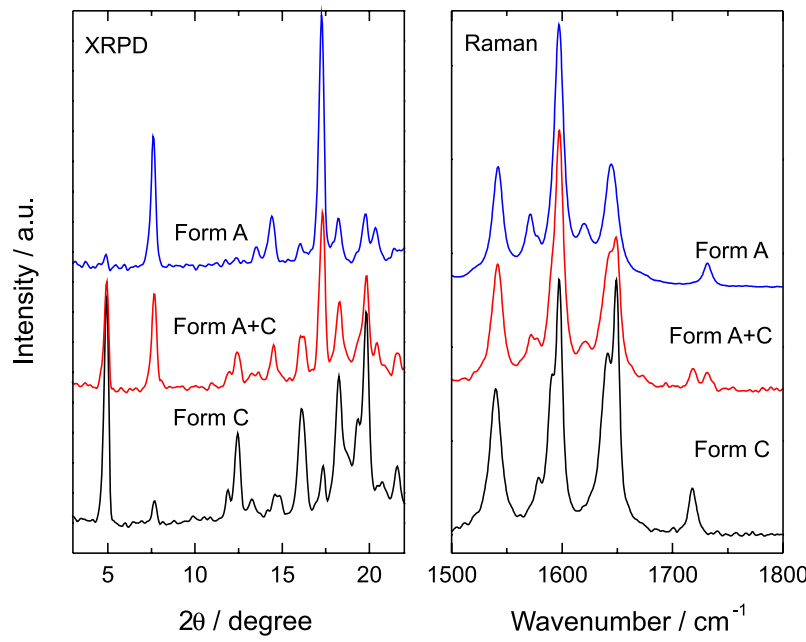

Figure 2. Representative X-ray powder diffraction patterns and Raman spectra of commercial tablets of MBZ.

Several authors have reported on the variable solubility of the polymorphs of MBZ,,$^{15,18,24,29}$ mainly focusing in the comparison of the solubility for the pure polymorphs in the USP and in the modified media. To the best of our knowledge, no research about the medium influence in the solubility of mixtures of these polymorphs was ever performed. Therefore, samples with concentration ranging from 0 to $100 \%$ of form $\mathrm{C}$ were submitted to dissolution tests, using media I and II. The corresponding dissolution profiles are shown in Figure 3. In general, one may notice that these profiles follow a certain expected behavior. In medium I, all the samples dissolved rapidly, reaching values around $80 \%$ after $120 \mathrm{~min}$. On the other hand, in medium II, the percentage of dissolved drug increased when the amount of polymorph A decreased. This effect may be easily explained by considering the lower solubility of form A when compared to form C. Nevertheless, a detailed inspection of the concentration dependence of the dissolution profile in medium I reveals an opposite behavior. In this medium, the solubility of the samples decreased, as the concentration of form A decreased, suggesting that the effect of the tensoactive agent in the dissolution of form $\mathrm{A}$ is stronger than in form $\mathrm{C}$.
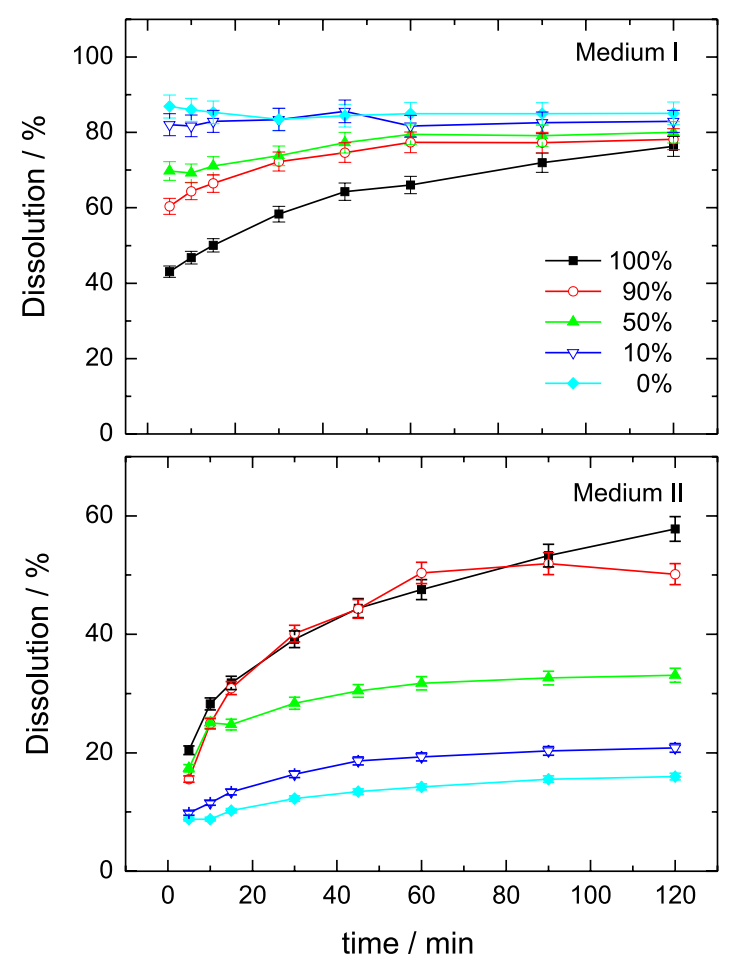

Figure 3. Powder dissolution profiles of $\mathrm{MBZ}$ as function of the polymorph $\mathrm{C}$ concentration in $0.1 \mathrm{~mol} \mathrm{~L}^{-1} \mathrm{HCl}$ containing $1 \%$ (medium I) and $0 \%$ (medium II) of SLS.

Figure 4 shows the concentration dependence on the percentage of the dissolved drug after $120 \mathrm{~min}$. Even exhibiting opposite behaviors, a linear relationship between the amount of form $\mathrm{C}$ and the solubility of the sample was observed. Considering this, it was described that at least $30 \%$ of form $\mathrm{A}$ in the tablets is enough to suppress the desirable pharmacological activity, ${ }^{15,19}$ it would be possible to use our results to build a model in order to determine

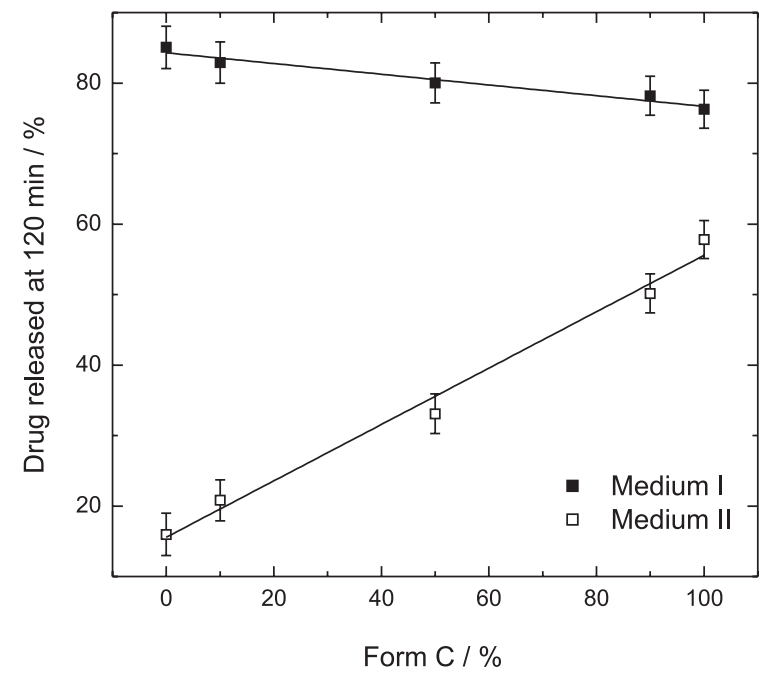

Figure 4. Percentage of the dissolved samples at $120 \mathrm{~min}$ as function of the MBZ form C concentration using the USP (medium I) and modified (medium II) methods. 
the concentration of form $\mathrm{C}$ from the dissolution profiles. However, since the dissolution profile may be affected by the formulation related parameters, the solubility is directly determined by the crystal packing of drug molecules in the different polymorphs. Experimental techniques that are sensitive to the crystal structure (like the vibrational spectroscopy or the XRPD) are advisable to perform this task.

The dissolution profiles of the polymorphic mixtures were quantitatively compared by calculating the $f_{1}$ and $f_{2}$ statistical parameters. The corresponding values are listed on Table 1 and plotted in Figure 5.

Table 1. The difference $\left(f_{1}\right)$ and the similarity $\left(f_{2}\right)$ factors calculated from mixtures of polymorph A and polymorph $\mathrm{C}$ of MBZ dissolved in media I and II

\begin{tabular}{lcccc}
\hline \multirow{2}{*}{ Polymorph C / \% } & \multicolumn{2}{c}{ Medium I } & \multicolumn{2}{c}{ Medium II } \\
\cline { 2 - 5 } & $f_{1}$ & $f_{2}$ & $f_{1}$ & $f_{2}$ \\
\hline 0 & 42.8 & 27.5 & 69.2 & 26.5 \\
10 & 39.0 & 29.4 & 59.6 & 29.7 \\
50 & 25.8 & 38.4 & 30.7 & 42.0 \\
90 & 19.8 & 44.3 & 6.8 & 71.3 \\
100 & 0 & 100.0 & 0 & 100.0 \\
\hline
\end{tabular}
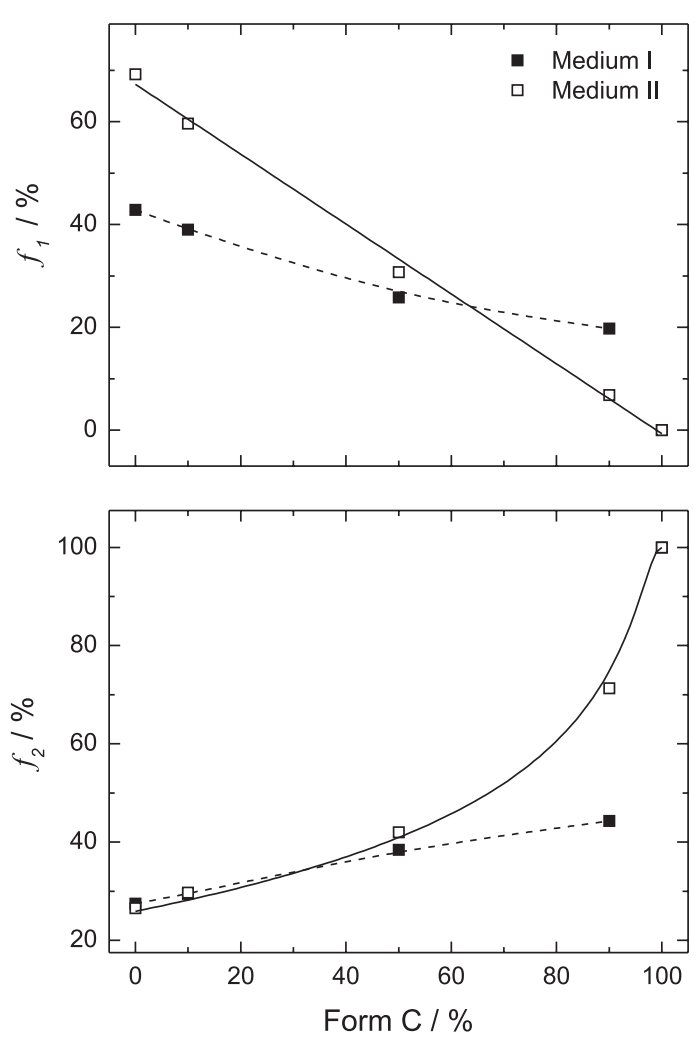

Figure 5. Dependence of the MBZ form $\mathrm{C}$ concentration is shown in accordance with the difference $\left(f_{l}\right)$ and similarity $\left(f_{2}\right)$ factors in media I ( $\left.\mathbf{\square}\right)$ and II ( $\square$ ). The solid lines were fitted using equations 4 and 5, while the dashed lines were guides for the eyes.
Hence, firstly the behavior of these parameters are discussed when the medium II is used. In this particular case, a continuous evolution in the difference and in the similarity parameters is observed. It is not an unexpected result, as the dissolution profile is determined by the relative concentration of forms A and C. Assuming a linear combination of the dissolution profiles of forms $\mathrm{A}$ and $\mathrm{C}$ :

$T(x)=\left(1-\frac{x}{100}\right) R^{A}(x)+\frac{x}{100} R^{C}(x)$

equations 1 and 2 can be rewritten as:

$f_{1}(x)=\left(1-\frac{x}{100}\right) f_{1}^{A}$

$f_{2}(x)=50 \times \log \left[\frac{100}{\sqrt{1+\alpha(1-x / 100)^{2}}}\right]$

where

$f_{1}^{A}=\left[\frac{\sum_{j=1}^{n}\left|R_{j}^{C}-R_{j}^{A}\right|}{\sum_{j=1}^{n} R_{j}^{C}}\right] \times 100$

$\alpha=\frac{1}{n} \Sigma_{j=1}^{n}\left(R_{j}^{C}-R_{j}^{A}\right)^{2}$

The parameters $f_{1}^{A}$ and $\alpha$ can be calculated from the experimental profiles of pure polymorphs. Thus, $f_{1}^{A}$ is the difference factor between the pure polymorphs $(69.2 \%)$ and, the calculated $\alpha$ value is 867 . On the flip side, the proposed behavior can be tested by fitting the experimental $f_{1}$ and $f_{2}$ curves (Figure 5), using equations 4 and 5 . In this case, it was obtained the following values $f_{1}^{A}=67(1)$ and $\alpha=920(90)$. The compatibility in the two sets of values is excellent, showing that in the modified medium (medium II), the dissolution profile is the linear combination of the dissolution profiles in the pure samples weighted by a relative concentration. This result also suggests that there is no interaction between the polymorphs.

The recorded dissolution profiles in medium I cannot be described using the proposed model. The concentration dependence of $f_{1}$ and $f_{2}$ does not follow the behavior that is represented by equations 4 and 5 . This result provides additional support to the hypothesis that the surfactant is acting differently in form A than in form C. Both $f_{1}$ and $f_{2}$ do not continuously tend to $100 \%$ with increasing of the concentration of form C. Even small amounts of form A have a strong impact in the solubility of the physical mixture. Notice that the main difference in the dissolution profiles is not given by the final value, instead of this, it is by the behavior at the start of the process. In this region, the dissolution is dominated by form A since it is more soluble in the presence of the surfactant. This is the main 
contribution to the lower (higher) values of $f_{l}\left(f_{2}\right)$ in the samples with a small concentration of form $\mathrm{C}$.

The polymorphism of MBZ and their implications on the bioavailability have been discussed by several authors. However, there are no reports of its incidence on commercial tablets. Moreover, the modified dissolution method (medium II) proposed by Swanepoel et al. ${ }^{18}$ was applied in this study (with the mixtures of form A and C), exhibiting an uneven discrimination potential, although it was not tested in commercial samples. In the case of formulated products, the effect of the excipients in the dissolution tests should be verified before considering the modifying of a pharmacopeic monograph. Therefore, the dissolution profiles of the nine different branded MBZ tablets, which were selected for this study using media I and II, are shown in Figure 6. Tablets having API/excipient ratios ranging from 1:1 up to $1: 2$ were researched. Our results in formulated products clearly confirm the conclusions raised in the research of raw materials. In medium I, all the tablets exhibited similar solubility profiles being in good agreement with the pharmacopoeia specifications $(\mathrm{Q}>75 \%)$. Despite the amount of excipients present in the tablets, medium II confirmed to be able in ensuring the crystal form in the case of formulated tablets with pure polymorphs A or C. It is important to notice that only the tablet that is formulated with form C could agree with the pharmacopoeia specifications since it

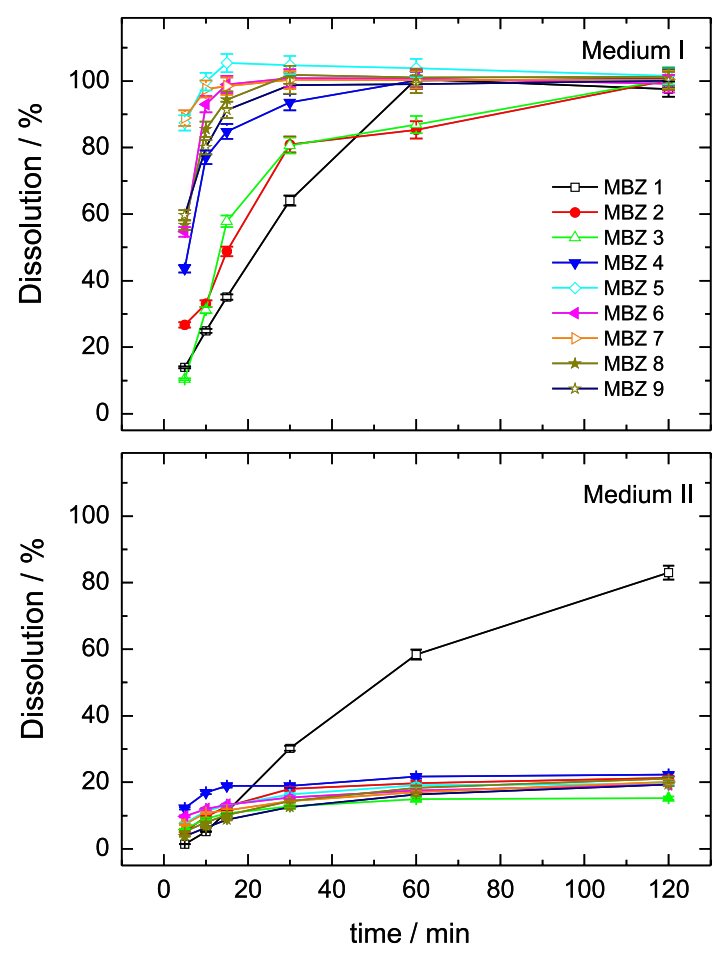

Figure 6. Powder dissolution profiles of the MBZ commercial tablets in $0.1 \mathrm{~mol} \mathrm{~L}^{-1} \mathrm{HCl}$ containing $1 \%$ (medium I) and $0 \%$ (medium II) of SLS. dissolved in more than $75 \%$ after 120 min. Notwithstanding, the complete method should be reviewed in order to consider not only form A and C, but also form B and the mixtures of polymorphs. None of our samples evidenced the presence of a third polymorph. However, our group observed this aforementioned particular effect in tablets that were not included in the dissolution tests (see Figure 2). According to Figure 3, a continuous dependence of the solubility is expected as a function of the form $\mathrm{C}$ concentration. Therefore, not only a simple percentage of dissolution, but also a concentration limit of the undesired polymorphs must be established. However, as previously stated, techniques like the vibrational spectroscopy without recrystallization in solvents (like the European Pharmacopoeia IR assay) or XRPD may provide a much more accurate method for identifying the MBZ polymorphs in both raw materials and formulated products.

Table 2 lists the $f_{1}$ and $f_{2}$ values that were calculated from the dissolution profiles of the researched commercial tablets. The formulated tablets with form C (MBZ 1) were used as a reference. In the case of the medium I, as it was previously shown in this study, all tablets fulfill the pharmacopeic condition of being not less than $75 \%(\mathrm{Q})$ dissolved after $120 \mathrm{~min}$. However, $f_{1}$ and $f_{2}$ clearly showed that the dissolution profiles present very distinctive features. In the samples with higher concentration of form A, it is expected a faster dissolution rate in the beginning due to the enhanced effect of the surfactant on this particular polymorph. If medium II is used in the test, the tablets will follow a similar behavior to that of the pure polymorphs. The solubility continuously and smoothly increases as a function of time, while tablets containing form $\mathrm{C}$ are more soluble than those containing form A.

Table 2. The difference $\left(f_{l}\right)$ and the similarity $\left(f_{2}\right)$ factors calculated from commercial tablets of MBZ dissolved in media I and II

\begin{tabular}{lcccc}
\hline \multirow{2}{*}{$\begin{array}{l}\text { Mebendazole } \\
\text { tablets }\end{array}$} & \multicolumn{2}{c}{ Medium I } & \multicolumn{2}{c}{ Medium II } \\
\cline { 2 - 5 } MBZ 1 & $f_{1}$ & $f_{2}$ & $f_{1}$ & $f_{2}$ \\
MBZ 2 & 0 & 100.0 & 0 & 100.0 \\
MBZ 3 & 20.7 & 45.0 & 64.7 & 26.0 \\
MBZ 4 & 19.6 & 44.0 & 72.7 & 23.6 \\
MBZ 5 & 48.0 & 23.4 & 73.4 & 24.0 \\
MBZ 6 & 79.3 & 13.3 & 69.2 & 25.3 \\
MBZ 7 & 62.9 & 17.7 & 72.1 & 24.9 \\
MBZ 8 & 74.5 & 14.2 & 69.8 & 25.0 \\
MBZ 9 & 60.9 & 18.9 & 66.2 & 25.5 \\
\hline
\end{tabular}

Albonico ${ }^{10}$ reported an apparent reduction in the efficacy of MBZ in the treatment of hookworm infections in the populations that are exposed to periodic deworming 
programs. This observation suggests the possibility of an emerging resistance of the infection to MBZ. Nevertheless, the used crystal form in this report is not explicitly reported. The used tablets in the trials of this study belong to companies which formulate MBZ using form C. On the other hand, no information is available about the crystal form in the tablets that were used in several deworming programs. Bennett and Guyatt ${ }^{4}$ suggested that the low efficacy of the anthelmintics in Asia could originate not only in genetic variations of the parasites, but also in the quality of the drugs. The differences in solubility among the crystal forms of MBZ (form C is more than twice as soluble than form A) will probably affect the bioavailability of this API. As previously suggested, this is due to the lack of anthelmintic activity in the tablets that were formulated with form A. The way by which these changes in the bioavailability of the tablets affects the efficiency of the deworming programs and how much it contributes to the appearing of resistances are still unanswered questions.

\section{Conclusions}

The polymorphism of MBZ is a very well-known issue and may have a direct impact in the efficacy of formulated products. Our results have clearly confirmed that prescribed dissolution test by several pharmacopoeias is not able to distinguish the polymorphic character of MBZ in commercial tablets. As a consequence, the markets with well-established generic products and the lack of reliable quality control specifications could give rise to the widespread use of polymorphic mixtures, whereby, therapeutic effects are still not well understood. In order to improve the standard methods, we tested a modified dissolution medium. This medium strongly enhanced the identification of the crystal structure.

Furthermore, the analysis of mixtures of forms A and $\mathrm{C}$ showed a continuous dependence of the solubility on the relative concentrations. However, opposite behaviors were observed in media I and II. The statistical analysis of recorded data showed that, in the absence of the surfactant, the dissolution profiles of the polymorphic mixtures can be described as a linear combination of those described pure forms. On the other hand, the used surfactant in the first medium seems to more efficiently solubilize form A than form $\mathrm{C}$, enhancing the solubility of the physical mixture. Further, the investigations on this field should be performed in order to provide a more precise description of the presented process herein.

The deworming programs and the oral therapy of helmintic infections (being these the neglected tropical diseases) are one of the main initiatives of WHO. These
WHO programs were benefited by the raise of the generic market, which may provide low cost drugs. However, it is necessary to ensure the effectiveness of these mentioned medicines. Mebendazole is an interesting case of study and research, showing that researchers and health-program administrators must be aware of the impact of polymorphism in effectiveness of a therapeutic treatment. In general, particularly the solid state properties of the active ingredients are important factors to guarantee the success of a deworming program.

\section{Acknowledgements}

The authors would like to thank partial financial support from Coordenação de Aperfeiçoamento de Pessoal de Nível Superior (CAPES), Conselho Nacional de Desenvolvimento Científico e Tecnológico (CNPq), Prosul/CNPq, Rede NanoBioEstruturas, Instituto Nacional de Ciência e Tecnologia (INCT) of NanoBioEstruturas and Simulação NanoBioMolecular and Fundação Cearence de Apoio ao Desenvolvimento Científico e Tecnológico (FUNCAP). S. L. Cuffini thanks Consejo Nacional de Investigaciones Científicas y Técnicas (CONICET), Fundación Sauberan, MinCyT-Córdoba.

\section{References}

1. Reddy, M.; Gill, S. S.; Kalkar, S. R.; Wu, W.; Anderson, P. J.; Rochon, P. A.; JAMA, J. Am. Med. Assoc. 2007, 298, 1911.

2. Awasthi, S.; Bundy, D. A. P.; Savioli, L.; British Med. J. 2003, $327,431$.

3. Hotez, P. J.; Bethony, J.; Bottazzi, M. E.; Brooker, S.; Buss, P.; PLoS Med. 2005, 2, 187.

4. Bennett, A.; Guyatt, H.; Parasitol. Today 2000, 16, 71.

5. Chan, M. S.; Parasitol. Today 1997, 13, 438.

6. Crompton, D. W. T.; Montresor, A.; Nesheim, M. C.; Savioli, L; Controlling Disease due to Helminth Infections; World Health Organization (WHO): Geneva, 2003.

7. Dayan, A. D.; Acta Trop. 2003, 86, 141.

8. Urbani, C.; Albonico, M.; Acta Trop. 2003, 86, 215.

9. World Health Organization (WHO) Technical Reports Series; Prevention and Control of Schistosomiasis and Soil-Transmitted Helminthiasis: Report of a WHO Expert Committee; World Health Organization: Geneva, 2002.

10. Albonico, M.; Acta Trop. 2003, 86, 233.

11. Albonico, M.; Engels, D.; Savioli, L.; Int. J. Parasitol. 2004, 34, 1205.

12. Brittain, H. G.; Polymorphisms in Pharmaceutical Solids, $1^{\text {st }}$ ed.; Marcel Dekker: New York, 1999.

13. Byrn, S. R.; Pfeiffer, R. R.; Stowell, J. G.; Solid-State Chemistry of Drugs, $2^{\text {nd }}$ ed.; SSCI Inc.: West Lafayette, 1999. 
14. Charoenlarp, P.; Waikagul, J.; Muennoo, C.; Srinophakun, S.; Kitayaporn, D.; Southeast Asian J. Trop. Med. Public Health 1993, 24, 712.

15. Evans, A. C.; Fincham, J. E.; Dhansay, M. A.; Liebenberg, W.; S. Afr. Med. J. 1999, 89, 1118.

16. Costa, J.; Fresno, M.; Guzman, L.; Igual, A.; Oliva, J.; Vidal, P.; Perez, A.; Pujol, M.; Circ. Farm. 1991, 49, 415.

17. Rodriguez-Caabeiro, F.; Criado-Fornelio, A.; Jimenez-Gonzalez, A.; Guzman, L.; Igual, A.; Perez, A.; Pujol, M.; Chemotherapy 1987, 33, 266.

18. Swanepoel, E.; Liebenberg, W.; de Villiers, M. M.; Eur. J. Pharm. Biopharm. 2003, 55, 345.

19. Ren, H.; Cheng, B.; Ma, J.; Hua, D.; Yiyao Gongye 1987, 18, 356.

20. Brits, M.; Liebenberg, W.; de Villiers, M. M.; J. Pharm. Sci. 2010, 99, 1138.

21. United States Pharmacopeial Convention, The United States Pharmacopoeia, USP 30, Rockville, MD, 2007.

22. Farmacopéia Brasileira, $4^{\text {th }}$ ed.; Atheneu Editora: São Paulo, Brasil, 2002.
23. Shah, V. P.; Konecny, J. J.; Everett, R. L.; McCullough, B.; Noorizadeh, A. C.; Skelly, J. P.; Pharm. Res. 1989, 6, 612.

24. Swanepoel, E.; Liebenberg, W.; Devarakonda, B.; De Villiers, M. M.; Pharmazie 2003, 58, 117.

25. Ayala, A. P.; Siesler, H. W.; Cuffini, S. L.; J. Raman Spectrosc. 2008, 39, 1157.

26. Martins, F. T.; Neves, P. P.; Ellena, J.; Cami, G. E.; Brusau, E. V.; Narda, G. E.; J. Pharm. Sci. 2009, 98, 2336.

27. de Villiers, M. M.; Terblanche, R. J.; Liebenberg, W.; Swanepoel, E.; Dekker, T. G.; Song, M.; J. Pharmaceut. Biomed. Anal. 2005, 38, 435.

28. Moore, J. W.; Flanner, H. H.; Pharm. Tech. 1996, 20, 64.

29. Liebenberg, W.; Dekker, T. G.; Lotter, A. P.; de Villiers, M. M.; Drug Dev. Ind. Pharm. 1998, 24, 485.

Submitted: February 23, 2011 Published online: November 22, 2011 